Orbis Tertius, vol. XXIV, $\mathrm{n}^{\circ}$ 30, e137, noviembre 2019-abril 2020. ISSN 1851-7811

Universidad Nacional de La Plata

Facultad de Humanidades y Ciencias de la Educación

Centro de Estudios dēeoría y Crítica Literaria

\title{
Juan Antonio Ennis y Laura Sesnich (eds.), Enriqueta la criolla y La hija de Giacumina: literatura popular, lenguas mixtas y naturalismo en dos folletos del 80. La Plata-Berlín, FaHCE.UNLP-Ibero Amerikanisches Institut Preußischer Kulturbesitz, 2017, Biblioteca Orbis Tertius, 274 páginas
}

Un año antes de que se expusiera en París el cuadro Le lever de la bonne (El despertar de la criada, 1887) de Eduardo Sívori, salieron a la luz las dos novelas que presenta esta edición. El cuadro de Sívori y las novelas de Giacumina y Enriqueta apuntan a la representación del cuerpo del delito, al decir de Ludmer, pero en los textos también aparece la lengua del delito; esa lengua de contacto que describe cuerpos de inmigrantes y criollas desviadas, mujeres que no se querían ver ni asimilar para la Nación.

La bonne está completamente desnuda. No sabemos qué dialecto habla, pero sus piernas gurdas, como las de Giacumina, sus brazos tostados hasta donde los cubre la ropa ausente revelan una condición social y una apuesta por la estética de lo imperfecto. El cuadro fue exhibido en Buenos Aires, pocos meses después de su exposición en el Salón de París, y fue considerado indecente y pornográfico por la crítica porteña. Unos años antes, el naturalismo como corriente estética había sido objeto de debates teóricos en el espacio de la prensa. Estas discusiones anticiparon expresiones textuales y pictóricas que sacudieron el mundo cultural de las élites porteñas, a partir de la publicación de Potpourri (1882) de E. Cambaceres (aunque también habría que pensar como antecedente la edición de El matadero, por un J. M. Gutiérrez lleno de reparos).Textos y obras plásticas habían empezado a girar hacia un novedoso registro fotográfico de la realidad y fueron aceptados progresivamente por la dirigencia liberal a lo largo de la década del ' 80 , en nombre de la anhelada ciencia.

Tanto La hija de Giacumina como Enriqueta la criolla no son ejemplares exclusivamente vinculados al naturalismo ni a las novelas de Balzac (autor que, por entonces, se leía en el Río de la Plata pero no se emulaban). Éstas se inscriben en el horizonte de un fenómeno ya popular, el de la novela sentimental en formato de folletín, que entre 1840 y 1880 contó con más de un centenar de ejemplares sólo en Buenos Aires. El "pecado de los folletines", al decir de Sarmiento, era su capacidad de seducción, su magnetismo desmedido y, como evidencian los artículos del sanjuanino, el temor de las élites por el efecto moral de la ficción sobrevolaba el ambiente, ya en la década de 1840. En aquellos primeros folletines tan temidos no aparecía ni la sombra de lo que mostró la literatura giacumina. Las ficciones de E. Mansilla, J. M. Gorriti, V. F. López, J. Pelliza, M. Cané, entre otros, seguían principios de decoro en cuanto a temas y lemas. Estas novelas del romanticismo latinoamericano, al decir de Doris Sommer, debían ofrecer modelos de moralidad y soluciones raciales. En ellas, la mujer debía representar a la patria y sus uniones sentimentales debían proyectar los ansiados lazos de progreso, control sexual e institucionalidad. Ni la escasa pero exitosa novela sentimental ni la literatura giacumina pervivieron en los archivos de la alta cultura, pero tuvieron un influjo contundente en el lectorado femenino y, de manera casi inconfesada, en el masculino.

Las novelas de esta edición se escribieron en el revés de aquellos modelos proyectivos. Emergieron por el despertar naturalista que planteaba, a su vez, una tensión con la lengua literaria deseada. Sin embargo, 
asumieron la audacia de estar escritas en una no-lengua y, mediante la distancia humorística del registro, permearon historias que el discurso nacional no aceptaba pronunciar.

Enriqueta la criolla sigue, de alguna u otra manera, a Potpurri de Cambaceres porque aborda los entretelones de las clases acomodadas de Buenos Aires. El relato plantea que la condición racial o social no son los únicos factores que puede arrastrar a una mujer a la "inmoralidad" sino, sobre todo, su mala educación y la complacencia de sus caprichos. Así como el Boletin de Jurisprudencia (1845) de J. Pacheco denominaba "pendiente del crimen" a la cadena de malas conductas que arrastraba a los jóvenes varones a la delincuencia, aquí se plantea una pendiente en clave femenina y de clase. Enriqueta la criolla es, así, una reescritura paródica de la roussoniana Julia: la educación de las niñas (1863) de Rosa Guerra, uno de los tantos manuales de conducta femenina que fueron por esos años toda una referencia para la burguesía.

La lengua de esta novela es el pastiche de Los amores de Giacumina, pero incluye misivas en castellano estándar entre las personas de clase alta. La señora María, que instala en su casa un "matadero désimulao" (p. 176), una casa de citas, lee también El cornudo (1844), de Paul Lecoq (citado como Paulo di Koque), y esta escena da cuenta de una práctica de las clases letradas pero, a su vez, de la perversión de la anhelada civilización. Las novelas que tocaban temas como la infidelidad no eran las recomendables para la educación de las damas pero María, espejo de la progresión de Enriqueta, presenta todo tipo de transgresiones. Como causa o consecuencia del desvío y el adulterio, las prácticas de lecturas «inapropiadas» entran en funcionamiento como incentivo y catalizador de costumbres que ya eran habituales en su círculo social.

Por otro lado, las reacciones violentas que tienen los padres de Enriqueta al enterarse que a su hija "li habían piantau la lichuga” (p. 184) se amplifican cuando su hermano, el diputado Don Carlos, va a buscar al responsable de la deshorna "para hacerle cumer la insalada" (p. 184), y cuando Enriqueta se venga de Julián. Las agresiones brotan en la familia como consecuencia de su imagen pública manchada y así los deshornados resuelven ir a pasar un tiempo a su casa de las afueras de la ciudad "hasta qui la mochacha obiera largao il rilleno" (p. 195). Todas las referencias a la violencia, la sexualidad, el embarazo y el aborto son burdas y exageradas, y la voz otra muestra, con lisura y placer, cómo esa clase estaba también inoculada de esos asuntos. Las "linguas largas" (p. 201), guardianas de la imagen pública, entran en la dinámica de la deshorna pero así y todo, los privilegios permiten a Enriqueta y sus padres seguir sosteniendo la aparente institucionalidad.

En La hija de Giacumina, por su parte, se desarrolla también la pendiente de infortunios de una joven que se inicia en la vida sexual por elección, como Enriqueta. Sin embargo, Giacumina es introducida en la prostitución, en la que logra cierto éxito, pero pierde su oficio cuando se enferma y así, cae en una serie de desgracias que la llevan a la muerte. La lengua de Giacumina es genesi y los personajes que aparecen en la obra son todos inmigrantes de primera o segunda generación. Todos se hacen entender, incluso las turcas que no hablaban "castilla ni genesi, ni italiano ni siquiera inglés pero hablaba con leocos di so cara" (p. 240). En el submundo del circo, la prostitución, la vida en la calle, la hija de Giacumina encuentra salvadores que son rufianes, ayudantes que son una trampa, y hasta pasa una noche con un marinero que narra una historia sobre sus viajes por Asia, relato por el cual los amantes descubren que son hermanos.

La condición de mujer pobre determina la vida de Giacumina, dominada por la violencia de los hombres que se encuentra a su paso y del Estado, que no se ocupa de ella. El final apunta a un lector acostumbrado a las resoluciones melodramáticas, pero también reafirma la hipótesis del condicionamiento biológico, como asegura la abuela y madre de las dos Giacuminas: "esta mochacha es lo mesmo que so mamas" (p. 216). Así, en la diégesis, la joven debe tener el mismo final que su madre o tal vezuno aún peor, ya que el hijo, fruto del incesto,es abandonado en una comisaría. Las dos novelas muestran, en suma, una crítica hacia la clase alta y al desamparo de la mujer inmigrante. Cada obra tiene su focalización particular, pero ambas presentan a mujeres que deciden dar cauce a su deseo sexual aunque éste tenga derroteros y soluciones divergentes según su condición.

La edición de acceso abierto en la Biblioteca Orbis Tertius de la Universidad Nacional de La Plata está a cargo de Juan Ennis y Laura Sesnich. Por la improbabilidad del método, las novelas carecen de un aparato 
de notas. Más que anotar las obras cabría traducirlas, lo que sería una labor sospechosa, como la que se ha hecho varias veces con La fiesta del monstruo de H. Bustos Domecq. La versión de los textos, sin embargo, enmienda erratas que pudieran impedir su legibilidad. De esta manera, los editores presentan documentos de una literatura marginal que, a su vez, fue más original y nacional — como la gauchesca-, que las producciones centrales. El dialecto de estas novelas es accesible a cualquier lector de español: la representación fonética de las hablas es reconocible. Pero, sin duda, estas novelas reclaman aún hoy la lectura en voz alta, tal como debieron haberse transmitido en su época, y como venía sucediendo con el folletín en la ciudad y en la campaña.

El estudio preliminar da cuenta de la andadura de estos textos y su emergencia en el archivo, y recoge la sugerencia de Adolfo Pietro sobre la Biblioteca criolla de Robert Lehmann-Nitsche, ubicada en el IberoAmerikanisches Institut de Berlín. La introducción plantea la vinculación de estos textos con los debates sobre la lengua y los aspectos estético-sociales del naturalismo en el Rio de la Plata, un enclave lúcido e indispensable para releer estas dos ficciones y otorgarles sustento filológico. La perspectiva gloto política del estudio plantea un asunto implícito en los folletos, es decir, la articulación lengua-pueblo que el Estado liberal quería legitimar, en un contexto donde inmigración y público se confundían, y en el que se ponía en duda la viabilidad de su representación. A su vez, el análisis plantea que la representación de las hablas "vincula lengua, espacio, cuerpo y conductas" (p. 38), algo que también revelan obras naturalistas canónicas; pero la diferencia es que aquí se produce mediante una transcodificación paródica de amplio alcance.

La puesta en página y la accesibilidad de este estado de lengua dan cuenta no sólo de las formas, sino también de nuevos mercados y una demanda por una literatura alejada de la función didáctica o, mejor aún, una propuesta ex negativo bajo presumibles intereses científicos, anche costumbristas. En Enriqueta la criolla y La hija de Giacumina, por demás, no sólo se señala esta doble dirección sino que también hay una distancia con la lengua literaria; el tono y el uso de las voces descoloca en más de un sentido pero propone, en suma, la inestabilidad de todos los modelos. 